\title{
Effect of Substrate Movement Speed by Synchronous Rolling-casting Freeform Manufacturing for Metal on Microstructure and Mechanical Property of ZLIO4 Aluminum Alloy Slurry
}

\author{
LUO Xiaoqiangi,2, LI Zhengyang.2", CHEN Guangnan², XU Wanli², YAN Qingzhi' ${ }^{*}$ \\ (1. School of Materials Science and Technology, University of Science and Technology Beijing, Beijing 100083, China;2.Institute of \\ Mechanics, Chinese Academy of Sciences, Beijing 100190, China)
}

\begin{abstract}
Synchronous rolling-casting freeform manufacturing for Metal (SRCFMM) means that the refined liquid metal is continuously pressed out from the bottom of crucible. There is a horizontal movable plate beneath the outlet. The clearance between the outlet and the plate is about several hundred micrometers. SRCFMM, similar to additive manufacturing, implies layer by layer shaping and consolidation of feedstock to arbitrary configurations, normally using a computer controlled movable plate. The primary dendritic crystal is easily crushed by movement of substrate in the rolling-casting area. ZL104 was used as the test materials, determining the control temperature by differential scanning thermal analysis (DSC), preparing a kind of samples by SR CFMM, then analyzing microstructures and mechanical property of the samples. Characteristics and distribution of the primary particles were assessed by optical microscopy (OM), scanning electron microscopy (SEM), energy dispersive spectrum (EDS) and image analysis software. Mechanical property of the samples was assessed by vickers hardness. The results show that the samples fabricated by SRCFMM have uniform structures and good performances with the velocity of the substrate controlled about $10 \mathrm{~cm} / \mathrm{s}$ and temperature at about $580{ }^{\circ} \mathrm{C}$.
\end{abstract}

Key words: synchronous rolling-casting; additive manufacturing technology; temperature; substrate movement speed

\section{Introduction}

Shortening the period of processing components with complicated shape and high performance is the goal of manufacturing technology. M Orme proposed the method of droplets without mould in $1990 \mathrm{~s}^{[1-3]}$, and C R Rice put forward the semi-solid slurry without mold molding method in $2000^{[4]}$. Now the slurry processing of aluminum alloys without mold molding method has been used for the fabrication of parts with better mechanical properties compared to parts made by conventional casting ${ }^{[5,6]}$. Conventional processes are the mechanical stirring and electromagnetic stirring

(O) Whan University of Technology and SpringerVerlag Berlin Heidelberg 2015 (Received: May 25, 2014; Accepted: June 7, 2015)

LUO Xiaoqiang (罗晓强): Ph D student; E-mail: 1xq.5566 @163.com

*Corresponding author:LI Zhengyang (李正阳): Assoc.Prof.; Ph D; E-mail: 903737505@qq.com; YAN Qingzhi (燕青芝):Prof.; Ph D; E-mail: qzyn@ustb.edu.cn

Funded by the National Natural Science Foundation of China (No. 51341009) in which the temperature is controlled between the liquidus temperature and solidus temperature ${ }^{[7,8]}$. The solid primary grain of the slurry has good mobility. The mechanical stirring and electromagnetic stirring processes can prepare products through the processing methods of extrusion, die casting, and die forgin. The technology of semi-solid slurry forming is a kind of processing technology with energy-saving and efficient production which has broad prospects. The semi-solid metal processing, including thixoforming and rheocasting, has been regarded as a unique charm manufacturing method to produce near-netshape structural components for various industrial applications ${ }^{[9]}$. Compared with conventional diecasting, semi-solid metal processing has a number of advantages, such as low porosity, heat treatability, consistency and soundness of mechanical properties, the ability to make complex component shapes and longer die life ${ }^{[10-13]}$.

Synchronous rolling-casting freeform manufacturing for Metal (SRCFMM) is a pioneer kind of metal processing technology we first created. 
The refined liquid metal is continuously pressed out from the outlet of bottom of crucible. A horizontal movable plate is under the outlet. With the aid of 3D manufacturing software, the melt is solidified and formed layer by layer without mold. The technology has integrated the parts of design, molding and processing without the forming mould, reduced energy consumption and the sophisticated processing equipment and had broad application prospects. Therefore, they are well suited to the aerospace, the automobile industry, aerospace and national defense transportation and other fields, etc ${ }^{[14-16]}$. Among the various classes of aluminum silicon alloys, the ZL104 alloy as an important hyper-eutectic aluminum alloy is used to fabricate the plane wall plate, cylinder shell and the spare parts such as cylinder block of auto-motive industry parts. Their high wear resistance and good mechanical properties are substantially attributed to the presence of hard primary silicon particles scattered in the matrix ${ }^{[17-20]}$.

In this work, slurry of ZL104 alloy was prepared by SRCFMM, as a new manufacturing technique, which is of short course, high performance and netshape.In the process, the micro rolling mass force produced by substrate movement has been studied in SRCFMM.

\section{Experimental}

\subsection{Principle of SRCFMM}

The equipment of SRCFMM includes a pressure controller system with a lifting lever, a heating system with crucible, heating furnace, argon gas protection system, and a machine control system with roll casting mold and movable plate. The SRCFMM was used to form parts by controlling the motion of 3D platform according to data information. 3D platform system consisted of PMAC (program multiple axes controller) and $3 \mathrm{D}$ movement platform . The process monitor system which consisted of a CCD camera and an image acquisition card is used to observe the spraying and deposition process of synchronous rolling-casting. The principle of SRCFMM is shown in Fig.1. The CAD model of part is designed and transformed into control system format model data. The melt metal flows into the tundish under the control of temperature system, the mixing system and the pressure system of the graphite crucible. Then the melted metal flows through the bottom of the tundish discharging mouth into the area of synchronous cast-rolling. A lot of complex processes simultaneously take place in this region, including crystallization, solute redistribution, ripening, inter dendritic fluid flow and solid movement. The dendritic structure formed is greatly affected by convection during the early stages of solidification. In the limit of vigorous convection and slow cooling, the grains become small. The dendrite become short grain due to the action of shear force at the direction of plate movement, so as to achieve the goal of fine grains. The technology enables molten metal two-dimensional cross section to pile up layer by layer along the height direction into a complex three-dimensional model.

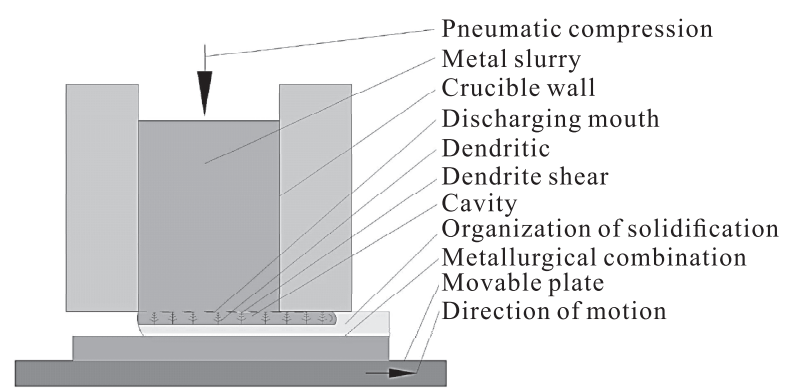

Fig. 1 Synchronous rolling-casting freeform manufacturing equipment

\subsection{Material}

This test used commodity ZL104 as raw materials, the composition of ZL104 aluminum silicon cast alloy investigated in this study is listed in Table 1. The density of the alloy was $2.72 \mathrm{~kg} / \mathrm{m}^{3}$.

Table 1 Composition of ZL104 aluminum alloy/wt\%

\begin{tabular}{cccccccc}
\hline $\mathrm{Si}$ & $\mathrm{Fe}$ & $\mathrm{Mn}$ & $\mathrm{Zn}$ & $\mathrm{Mg}$ & $\mathrm{Ni}$ & $\mathrm{Cu}$ & $\mathrm{Al}$ \\
\hline 9.1 & 0.5 & 0.3 & 0.25 & 0.2 & 0.2 & 0.1 & Bal. \\
\hline
\end{tabular}

\subsection{Slurry preparation}

The ZL104 aluminum silicon casting alloys were heated to a temperature between solidus temperatures and liquidus temperatures in order to obtain fine and globular microstructure which is required for the forming. Therefore, this heated temperature window could be controlled within between solidus temperatures and liquidus temperatures to get a proper solid fraction. As the Scheil equation, the volume fraction of liquid in the semi-solid microstructure should be a constant value at a given temperature during semi-solid isothermal heat treatment, with the assumption that the homogenization of the liquid is complete and no diffusion is in the solid.

\section{4 'Testing methods}

The solidus and liquidus temperatures of this alloy were measured by differential scanning thermal 
analysis(STA409PC), with argon gas protection in the testing process.

Two different districts of the samples were chosen to be investigated, samples for microstructural observation were prepared by standard metallographic techniques. The microstructures of samples were polished and etched in the solution of $0.5 \% \mathrm{HF}$, for $10 \mathrm{~s}$, then analyzed by optical microscopy, and the representative microstructure of the slurry can be obtained. All the metallographic samples were examined by NEOPHOT2 optical microscope(OM). The LEO-1450 scanning electron microscopy (SEM) and energy dispersive spectrometer (EDS) were used to confirm the phase analysis. T1 thermal treatment of the samples involved artificial aging. The samples were cooled in the air after high temperature forming process. They are cooled with natural aging to a stable state. T1 thermal treatment could enhance the intensity of ZL104 alloys. The samples for mechanical property tests were obtained from the middle region. The hardness was tested by a XHB-3000 Brilled duromete.

\section{Results and discussion}

\subsection{Differential scanning thermal analysis}

The solidus and liquidus temperatures of this alloy were 571.2 and $604.1{ }^{\circ} \mathrm{C}$ respectively, which was measured by differential scanning thermal analysis(DSC). The melting point of the pure metal and liquidus temperature of the alloy are TM and TL, respectively. In this experiment, we choose $580{ }^{\circ} \mathrm{C}$ as the processing temperature.

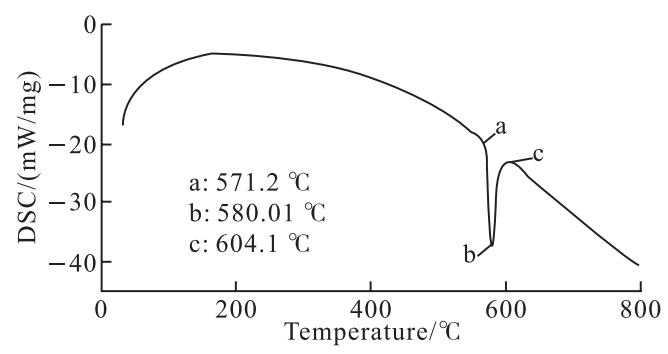

Fig. 2 DSC curve of ZL 104

\subsection{Microstructure of ZLIO4 alloy}

Fig. 3 shows backscattered electron(BSE) image and EDS spectra of the sample with two regions of ZL104 aluminum alloys which were produced in the process of this sample without substrate movement speed at $580{ }^{\circ} \mathrm{C}$. ZL104 alloy exhibits typical dendritic microstructure. Furthermore, it is found from Fig.3(a) that the grey precipitates is $\alpha-\mathrm{Al}$, white needleshaped precipitates is $\mathrm{Si}$, bright lump precipitation is $\mathrm{AlSi}_{9} \mathrm{Mg}$, in the main, and the microstructure of ZL104 alloy is mainly composed of matrix and eutectic Si phase. According to the EDS results of ZL104 aluminum alloy, it is confirmed that the arrow" $A$ " (grey precipitates) and arrow"B" (white needle-shaped precipitates) in Fig.3(b) are $\mathrm{AlSi}_{9} \mathrm{Mg}$ and eutectic $\mathrm{Si}$ phases, respectively. It is found from Fig. 3 that when the substrate movement speed of SRCFMM is $0 \mathrm{~cm} / \mathrm{s}$, ZL104 aluminum alloy has microstructure in complex irregular shape ,the Si phase is needle-shaped and the $\alpha-\mathrm{Al}$ is grey precipitates alloy mainly exhibiting a large block shape.

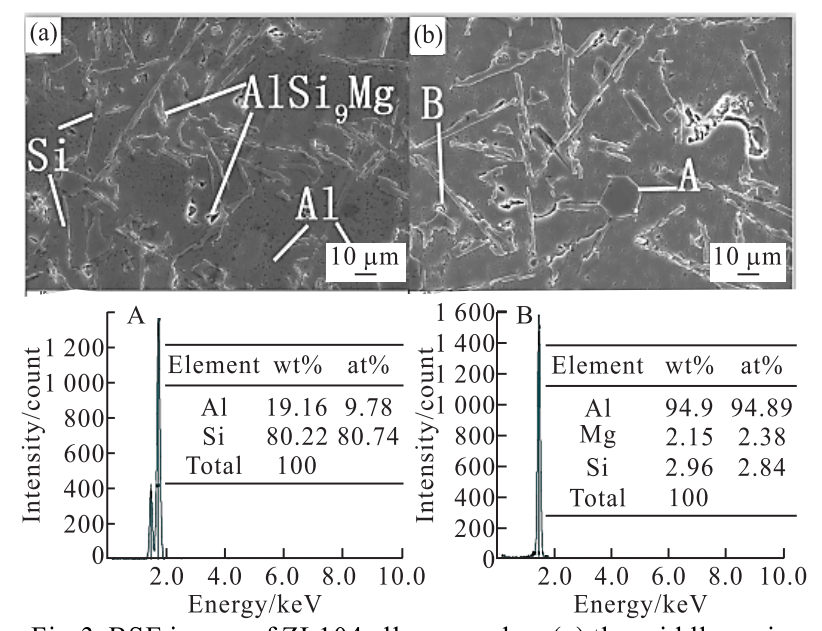

Fig. 3 BSE image of ZL104 alloy samples: (a) the middle region; (b) the energy spectrum test region; (A and B) the EDS results

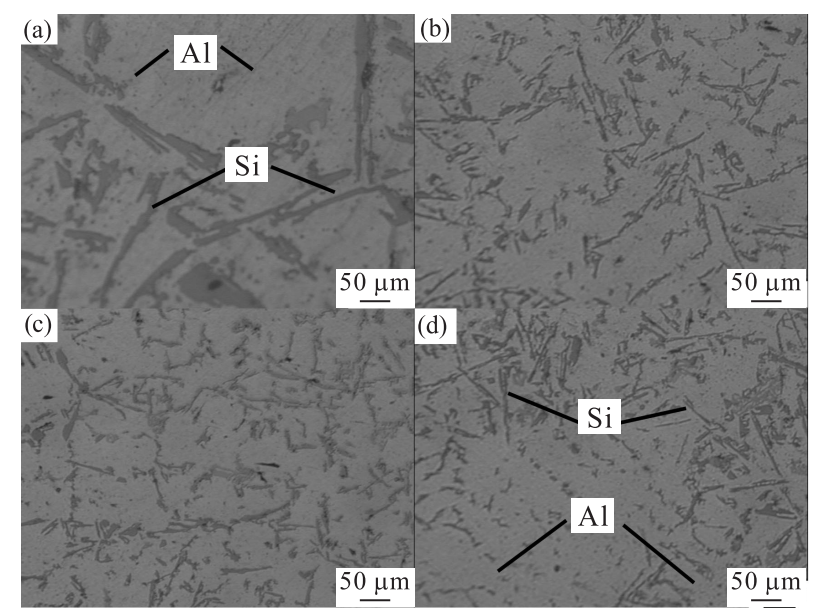

Fig.4 OM images of the ZL104 experimental alloy treated at substrate movement speed: (a) $0 \mathrm{~cm} / \mathrm{s}$; (b) $5 \mathrm{~cm} / \mathrm{s}$;

(c) $10 \mathrm{~cm} / \mathrm{s} ;$ (d) $15 \mathrm{~cm} / \mathrm{s}$

Fig. 4 shows the optical microstructure images of four samples. The four samples were made by SRCFMM with a different substrate movement speed. Four samples were high temperature molded without cold working besides cooling (T1 state). The speed of substrate movement by synchronous rolling-casting freeform manufacturing has a significant influence 
on material morphology. The process of SRCFMM is focused on solidification and melting. The speed of substrate movement made the dendrite become short grain under the action of shear force at the direction of plate movement, so as to achieve the goal of fine grains. The process enables molten to pile up layer by layer along the height direction into a complex model. Metallic melts rapidly forms dendrite between the mouth and crystallization plate cavity synchronous cast-rolling area .The observation of metallographic showed a lot of dendritic grains in Fig.4(a) and a typical dendritic microstructure. According to the EDS results of experimental alloy, it is confirmed that in Fig.3(b) the grey precipitates (A) and black needleshaped precipitates(B) are $\alpha$-Al and Si respectively.
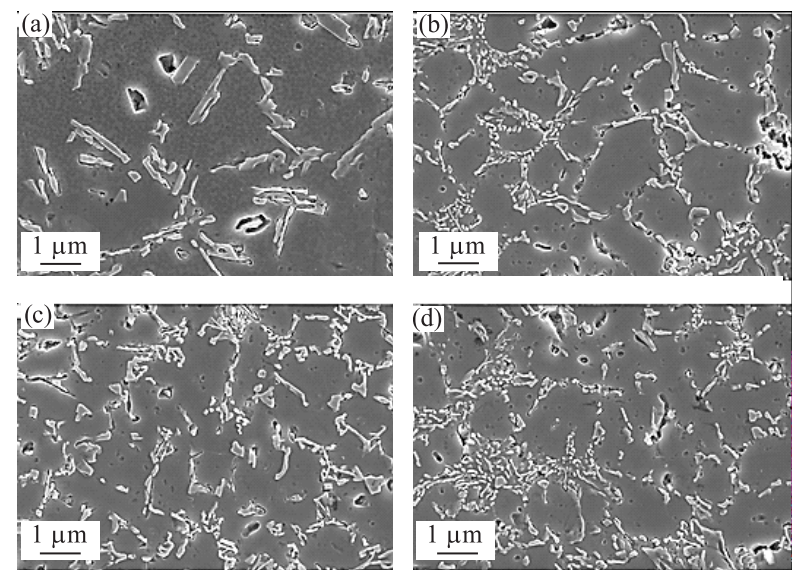

Fig.5 SEM images of the ZL104 experimental alloy treated at substrate movement speed: (a) $0 \mathrm{~cm} / \mathrm{s}$; (b) $5 \mathrm{~cm} / \mathrm{s}$; (c) $10 \mathrm{~cm} / \mathrm{s} ;$ (d) $15 \mathrm{~cm} / \mathrm{s}$

Fig. 5 shows the scanning electron microscopy of four samples magnified by 2000 times. The four samples were made by SRCFMM with a different substrate movement speed. Four samples were high temperature molded without cold working besides cooling (T1 state). The speed of substrate movement by synchronous rolling-casting freeform manufacturing with speed could change the cooling rate of melt. The fast movement of substrate interface bonding part could prevent the speed of heat dissipation. During the cooling process, rapid cooling is beneficial to grain refinement and the fast movement of substrate interface can make the grain refinement but the too fast movement of substrate interface could make the grain organization segregation, therefore reducing the mechanics performance of material.

According to the results, the experimental alloy treated at $580{ }^{\circ} \mathrm{C}$ with the substrate speed at $10 \mathrm{~cm} /$ $\mathrm{s}$ has a uniform microstructure and there is very few dendritic. Obviously, the temperature at $580{ }^{\circ} \mathrm{C}$ and the substrate speed at $10 \mathrm{~cm} / \mathrm{s}$ could maintain the balance of melting and solidification of the material .

\subsection{Hardness}

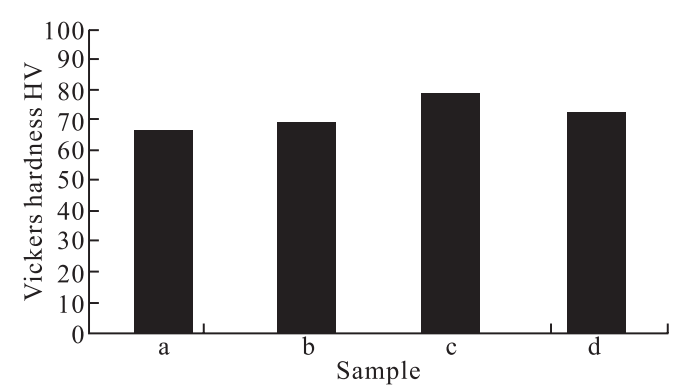

Fig.6 Chart of vickers hardness comparison of the ZL104 experimental alloy treated at substrate movement speed: (a) $0 \mathrm{~cm} / \mathrm{s}$; (b) $5 \mathrm{~cm} / \mathrm{s}$; (c) $10 \mathrm{~cm} / \mathrm{s}$; (d) $15 \mathrm{~cm} / \mathrm{s}$

Fig.6 is the comparison figure of four kinds of samples preparation for SRCFMM. The sample analysis of vickers hardness was made in the same place of the samples. From the figure it can be seen that the average vickers hardness of five positions in each sample is more than $65 \mathrm{HV}$, the largest average vickers hardness, sample(d), is $78.85 \mathrm{HV}$. According to the data of four samples, the highest vickers hardness located in the center of sample. It can be concluded that refinement of particles could increase material strength significantly, but the segregation of microstructure could decrease the material strength.

\section{Conclusions}

a) ZL104 alloy was produced by synchronous rolling-casting freeform manufacturing. The equipment process control temperature point was determined according to the differential thermal analysis (DSC) data. The temperature of the preparation of ZL104 slurry should be controlled at $580{ }^{\circ} \mathrm{C}$, at these temperatures, the slurry can maintain the proper viscosity and maintain excellent formability,

b) The micro rolling mass force produced by substrate movement could contribute to grain refinement in the process. The microstructure and mechanical performance are excellent when the base plate movement speed is controlled at $10 \mathrm{~cm} / \mathrm{s}$ in Synchronous rolling-casting freeform manufacturing for aluminum alloy slurry.

\section{References}

[1] M Orme. Method for Droplet Stream Manufacturing[P]. US Patent 5171360,1992 
[2] M Orme. On the Genesis of Droplet Stream Micro Speed Dispersions[J]. Physics of Fluids A-Fluid Dynamics, 1991, 3 (12) : 2 936-2 947

[3] M Orme, A Novel Technique of Rapid Solidification Net-Form Materials Synthesis[J]. Journal of Materials Engineering and Performance, 1993, 2 (3) : 399-407

[4] Rice C S, Mendez P F, Brown S B. Metal Solid Freeform Fabrication Using Semi-solid Slurries[J]. JOM, 2000, 52 (12) : 31-33

[5] HAQUE M M, SHARIF A. Study on Wear Properties of Aluminiumsilicon Piston Alloy [J]. Journal of Materials Processing Technology, 2001, 118(1/3): 69-73

[6] ATKINSON H V. Modelling the Semisolid Processing of Metallic Alloys [J]. Progress in Materials Science, 2005, 50(3): 341-412

[7] YANG Xiao-rong, MAO Wei-min, PEI Sheng. Preparation of Semisolid A356 Alloy Feedstock Cast Through Vertical Pipe [J]. Materials Science and Technology, 2007, 23(9): 1 049-1 053

[8] LUO Shou-jing, TIAN Wen-tong, XIE Shui-sheng, et al. Semi-solid Processing Technology and Application [J]. The Chinese Journal of Nonferrous Metals, 2000,10(6): 765-769

[9] YANG Xiao-rong, MAO Wei-min, PEI Sheng. Influence of Process Parameters on Microstructure of Semisolid A356 Alloy Slug Cast Through Vertical Pipe [J]. Transactions of Nonferrous Metals Society of China, 2008,18(1): 99-103

[10] LUKASSON M, APELIAN D, DASGUPTA R. Alloy Characterization for the New UBE Rheocasting Process [J]. AFS Transactions, 2002, 110: $271-284$

[11] LEGORETTA E C, ATKINSON H V, JONES H. Cooling Slope Casting to Obtain Thixotropic Feedstock. II: Observations with A356 Alloy [J]. Journal of Materials Science, 2008, 43(16): 5 456-5 469

[12] Masoud Mohammadi Rahvard, Morteza Tamizifar, Seyed Mohammad
Ali Boutorabi, et al. Characterization of the Graded Distribution of Primary Particles and Wear Behavior in the A390 Alloy Ring with Various Mg Contents Fabricated by Centrifugal Casting [J].Materials \& Design, 2014, 56:105-111

[13] M Mohammadi Rahvard, M Tamizifar, M A Boutorabi, et al. Effect of Superheat and Solidified Layer on Achieving Good Metallic Bond Between A390/A356 Alloys Fabricated by Cast-decant-cast Process [J]. Transactions of Nonferrous Metals Society of China, 2014, 24(3): 665672

[14] Finke S, Feenstra F K. Solid Freeform Fabrication by Extrusion and Deposition of Semi-solid Alloys[J]. Journal of Materials Science, 2002, 37(15): 3 101-3 106

[15] Flemings M C,Goodwin F E. Method for Making Alloy Compositions and Composition[P]. U S Patent, 4295896, 1981-10-20

[16] Kirkwood D H, Suery M, Kapranos P, et al. Semi-solid Processing of Alloys: Evolution of Microstructure in Semi-solid Alloys During Isothermal Holding [J]. Materials Science, 2010, 124:23-34

[17] M Gupta, S Ling. Microstructure and Mechanical Properties of Hypo/ Hyper-eutectic Al-Si [J]. Journal of Alloys and Compounds, 1999, 287:284-294

[18] Zhongtao Zhang, Tingju Li, Honyun Yue, et al. Study on the Preparation of Al-Si Functionally Graded Materials Using Power Ultrasonic Field [J]. Materials \& Design, 2009, 30(3): 851-856

[19] A M Samuel, H W Doty, S Valtierra, et al. Relationship Between Tensile and Impact Properties in Al-Si-Cu-Mg Cast Alloys and Their Fracture Mechanisms [J]. Materials \& Design, 2014, 53: 938-946

[20] A M Samuel, H W Doty, S Valtierra, et al. Defects Related to Incipient Melting in Al-Si-Cu-Mg Alloys [J]. Materials \& Design, 2013, 52: 947-956 